\title{
Min and Max Log-Logistic Extreme Interval Values
}

Marsha L. Jance, Indiana University East, USA

Nick T. Thomopoulos, Illinois Institute of Technology, USA

\begin{abstract}
The min and max log-logistic extreme interval values are presented. In addition, the paper shows how the log-logistic extreme interval values can be found from the uniform extreme interval values. An application and tables containing some of the min and max log-logistic and uniform extreme interval values are provided.
\end{abstract}

Keywords: Min and Max Log-logistic Extreme Interval Values; Log-logistic Values

\section{INTRODUCTION}

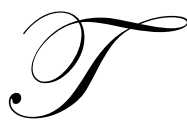

below $\mathrm{g}_{0.30}$.

his paper discusses the min and max log-logistic extreme interval values. An extreme interval value is an upper bound where a percentage of the data is below this value. For example, given the probability $\mathrm{P}\left(\mathrm{g}<\mathrm{g}_{0.30}\right)=0.30, \mathrm{~g}_{0.30}$ is the extreme interval value and $30 \%$ of the data is

Jance presented the min and max extreme interval values for the uniform, standard normal, and exponential distributions in the doctoral dissertation Calculating Min and Max Extreme Interval Values for Various Distributions. In addition, Jance and Thomopoulos showed the triangular min and max extreme interval values for different observation sizes $\mathrm{n}$ and probabilities. Jance developed Excel VBA programs to find the min and max extreme interval values and statistics for these distributions.

The min and max log-logistic values are first discussed and then the log-logistic extreme interval values are presented. Then it is shown how the log-logistic extreme interval values can be found from the uniform extreme interval values. Finally, an application using the log-logistic extreme interval values is discussed.

\section{MIN AND MAX LOG-LOGISTIC VALUES}

Suppose samples with n observations are taken from a continuous probability distribution (e.g. log-logistic) with probability density function $\mathrm{f}(\mathrm{x})$ and cumulative distribution function $\mathrm{F}(\mathrm{x})$ and the smallest (min) and largest (max) observations are selected. The min and max values will most likely vary from sample to sample. The min and max values will have a probability density function, cumulative distribution function, expected value, and variance. The min probability density function is $\mathrm{h}(\mathrm{g})=\mathrm{nf}(\mathrm{g})(1-\mathrm{F}(\mathrm{g}))^{(\mathrm{n}-1)}$ and the max probability density function is $\mathrm{h}(\mathrm{g})=\operatorname{nf}(\mathrm{g})(\mathrm{F}(\mathrm{g}))^{(\mathrm{n}-1)}$ (Hines, Montgomery, Goldsman, and Borror 215).

The following are the min and max log-logistic probability density functions, respectively:

$$
h(g)=n\left(\frac{\alpha\left(\frac{g}{\beta}\right)^{\alpha-1}}{\beta\left(1+\left(\frac{g}{\beta}\right)^{\alpha}\right)^{2}}\right)\left(1-\frac{1}{1+\left(\frac{g}{\beta}\right)^{-\alpha}}\right)^{n-1}
$$




$$
h(g)=n\left(\frac{\alpha\left(\frac{g}{\beta}\right)^{\alpha-1}}{\beta\left(1+\left(\frac{g}{\beta}\right)^{\alpha}\right)^{2}}\right)\left(\frac{1}{1+\left(\frac{g}{\beta}\right)^{-\alpha}}\right)^{n-1}
$$

When the log-logistic parameters are $\alpha=1$ and $\beta=1$, these reduce to the following:

$$
\begin{gathered}
h(g)=n\left(\frac{1}{(1+g)^{2}}\right)\left(1-\frac{1}{1+(g)^{-1}}\right)^{n-1} \\
h(g)=n\left(\frac{1}{(1+g)^{2}}\right)\left(\frac{1}{1+(g)^{-1}}\right)^{n-1}
\end{gathered}
$$

The min and max cumulative distribution functions $\mathrm{H}(\mathrm{g})$, expected values $\mathrm{E}(\mathrm{g})$, and variances $\mathrm{V}(\mathrm{g})$ are as follows:

$$
\begin{gathered}
\mathrm{H}(\mathrm{g})=\int_{0}^{\mathrm{g}} \mathrm{h}(\mathrm{g}) \mathrm{dg} \\
\mathrm{E}(\mathrm{g})=\mu=\int_{0}^{\infty} \mathrm{gh}(\mathrm{g}) \mathrm{dg} \\
\mathrm{V}(\mathrm{g})=\int_{0}^{\infty} \mathrm{g}^{2} \mathrm{~h}(\mathrm{~g}) \mathrm{dg}-\left(\int_{0}^{\infty} \mathrm{gh}(\mathrm{g}) \mathrm{dg}\right)^{2}
\end{gathered}
$$

\section{LOG-LOGISTIC EXTREME INTERVAL VALUES}

An Excel VBA program was developed to find the min and max log-logistic extreme interval values. The min and max log-logistic extreme interval values are found by first finding the min and max log-logistic cumulative distribution function values for $\mathrm{g}$ starting at $\mathrm{g}=0$ and incrementing by 0.0001 for the min and 0.01 for the max for all $\mathrm{H}(\mathrm{g})=0.01$ to $\mathrm{H}(\mathrm{g})=0.99$. Then the following interpolation formula is used to find the extreme interval values:

$\mathrm{g}_{\mathrm{p}}=\mathrm{g}_{1}+\left(\mathrm{g}_{2}-\mathrm{g}_{1}\right) \times \frac{\left(\mathrm{p}-\mathrm{H}\left(\mathrm{g}_{1}\right)\right)}{\left(\mathrm{H}\left(\mathrm{g}_{2}\right)-\mathrm{H}\left(\mathrm{g}_{1}\right)\right)}$ where $\mathrm{g}_{1}<\mathrm{g}_{\mathrm{p}}<\mathrm{g}_{2}$ and $\mathrm{H}\left(\mathrm{g}_{1}\right)<p<H\left(\mathrm{~g}_{2}\right)$ (Law and Kelton 470).

In the VBA program, $\mathrm{H}\left(\mathrm{g}_{2}\right)$ is the smallest cumulative distribution function value above the probability $\mathrm{p}$, and $\mathrm{H}\left(\mathrm{g}_{1}\right)$ is the largest cumulative distribution function value below p. MATLAB's Excel Link is used in conjunction with VBA to find the max cumulative distribution function values.

Tables 1 and 2 contain some of the min and max log-logistic extreme interval values for different observation sizes $\mathrm{n}$ and probabilities $\mathrm{p}$ in the case where the $\log$-logistic parameters are $\alpha=1$ and $\beta=1$. For example, when $\mathrm{n}=25$ and the probability is $\mathrm{p}=0.50$, the min extreme interval value is 0.02811 and the max extreme interval value is 35.56969 . One will notice that the min extreme interval values move closer to zero and the max extreme interval values increase as the observation size $\mathrm{n}$ increases. 
Table 1: Min Log-Logistic Extreme Interval Values when $\alpha=1$ and $\beta=1$

\begin{tabular}{cccccccc}
\hline \hline $\mathbf{n}$ & $\mathbf{p = 0 . 0 1}$ & $\mathbf{p = 0 . 0 5}$ & $\mathbf{p = 0 . 1 0}$ & $\mathbf{p = 0 . 5 0}$ & $\mathbf{p = 0 . 9 0}$ & $\mathbf{p = 0 . 9 5}$ & $\mathbf{p = 0 . 9 9}$ \\
\hline 1 & 0.01010 & 0.05263 & 0.11111 & 1.00000 & 9.00000 & 19.00000 & 99.00000 \\
2 & 0.00504 & 0.02598 & 0.05409 & 0.41421 & 2.16228 & 3.47214 & 9.00000 \\
3 & 0.00336 & 0.01724 & 0.03574 & 0.25992 & 1.15443 & 1.71442 & 3.64159 \\
4 & 0.00252 & 0.01291 & 0.02669 & 0.18921 & 0.77828 & 1.11474 & 2.16228 \\
5 & 0.00201 & 0.01031 & 0.02130 & 0.14870 & 0.58489 & 0.82056 & 1.51189 \\
10 & 0.00101 & 0.00514 & 0.01059 & 0.07177 & 0.25893 & 0.34928 & 0.58489 \\
25 & 0.00040 & 0.00205 & 0.00422 & 0.02811 & 0.09648 & 0.12730 & 0.20226 \\
50 & 0.00020 & 0.00103 & 0.00211 & 0.01396 & 0.04713 & 0.06175 & 0.09648 \\
75 & 0.00013 & 0.00068 & 0.00141 & 0.00928 & 0.03118 & 0.04075 & 0.06333 \\
100 & 0.00010 & 0.00051 & 0.00105 & 0.00696 & 0.02329 & 0.03041 & 0.04713 \\
\hline
\end{tabular}

Table 2: Max Log-Logistic Extreme Interval Values when $\alpha=1$ and $\beta=1$

\begin{tabular}{cccccccc}
\hline \hline $\mathbf{n}$ & $\mathbf{p = 0 . 0 1}$ & $\mathbf{p = 0 . 0 5}$ & $\mathbf{p = 0 . 1 0}$ & $\mathbf{p = 0 . 5 0}$ & $\mathbf{p = 0 . 9 0}$ & $\mathbf{p = 0 . 9 5}$ & $\mathbf{p = 0 . 9 9}$ \\
\hline 1 & 0.01010 & 0.05265 & 0.11112 & 1.00000 & 9.00000 & 19.00000 & 99.00000 \\
2 & 0.11108 & 0.28800 & 0.46247 & 2.41422 & 18.48683 & 38.49359 & 198.49874 \\
3 & 0.27455 & 0.58328 & 0.86622 & 3.84733 & 27.97659 & 57.98860 & 297.99777 \\
4 & 0.46245 & 0.89706 & 1.28488 & 5.28522 & 37.46708 & 77.48397 & 397.49686 \\
5 & 0.66141 & 1.21867 & 1.70971 & 6.72503 & 46.95786 & 96.97948 & 496.99598 \\
10 & 1.70971 & 2.86301 & 3.86212 & 13.93273 & 94.41309 & 194.45768 & 994.49171 \\
25 & 4.94402 & 7.85519 & 10.36504 & 35.56969 & 236.78089 & 486.89331 & 2486.97910 \\
50 & 10.36503 & 16.19540 & 21.21856 & 71.63591 & 474.06125 & 974.28637 & 4974.45812 \\
75 & 15.79116 & 24.53894 & 32.07464 & 107.70290 & 711.34172 & 1461.67949 & 7461.93707 \\
100 & 21.21856 & 32.88332 & 42.93137 & 143.77008 & 948.62225 & 1949.07262 & 9949.41603 \\
\hline
\end{tabular}

\section{FINDING THE LOG-LOGISTIC EXTREME INTERVAL VALUES FROM THE UNIFORM EXTREME INTERVAL VALUES}

The log-logistic extreme interval values can also be found from the uniform extreme interval values. Tables 3 and 4 contain some of the min and max uniform extreme interval values found by Jance when the uniform parameters are $\mathrm{a}=0$ and $\mathrm{b}=1$. For example, when $\mathrm{n}=25$ and the probability is $\mathrm{p}=0.50$, the min uniform extreme interval value is $\mathrm{g}_{0.50}=0.02735$ and the max uniform extreme interval value is $\mathrm{g}_{0.50}=0.97265$.

A log-logistic value can be found by using the inverse transform method: $\quad x=\gamma+\beta\left(\frac{u}{1-u}\right)^{1 / \alpha}$ where $u$ is a uniformly distributed variable with parameters $a=0$ and $b=1$ (Law and Kelton 468). Thus, the min and max loglogistic extreme interval values can be found by using the following:

$$
\mathrm{g}_{\mathrm{p}}=\gamma+\beta\left(\frac{\mathrm{g}_{\mathrm{p}, \mathrm{u}}}{1-\mathrm{g}_{\mathrm{p}, \mathrm{u}}}\right)^{1 / \alpha}=\frac{\mathrm{g}_{\mathrm{p}, \mathrm{u}}}{1-\mathrm{g}_{\mathrm{p}, \mathrm{u}}}
$$

where $\gamma=0, \alpha=1$, and $\beta=1$. Note, $g_{p, u}$ is the uniform extreme interval value for a particular probability $\mathrm{p}$, observation size $n$, and uniform parameters $a=0$ and $b=1$.

Suppose $n=25$, the probability $\mathrm{p}=0.50, \gamma=0, \alpha=1$, and $\beta=1, \quad$ then the min $\log$-logistic extreme interval value is

$$
\mathrm{g}_{0.50}=\frac{\mathrm{g}_{\mathrm{p}, \mathrm{u}}}{1-\mathrm{g}_{\mathrm{p}, \mathrm{u}}}=\frac{0.02735}{1-0.02735}=0.02812
$$

and the max log-logistic extreme interval value is 


$$
\mathrm{g}_{0.50}=\frac{\mathrm{g}_{\mathrm{p}, \mathrm{u}}}{1-\mathrm{g}_{\mathrm{p}, \mathrm{u}}}=\frac{0.97265}{1-0.97265}=35.56307
$$

Note, $g_{p, u}=0.02735$ is the min uniform extreme interval value and $g_{p, u}=0.97265$ is the max uniform extreme interval value for $\mathrm{n}=25$, probability $\mathrm{p}=0.50, \mathrm{a}=0$, and $\mathrm{b}=1$. Tables 5 and 6 contain the min and max $\log$ - $\operatorname{logistic}$ extreme interval values found from the uniform extreme interval values. One will notice that the values in Tables 1 and 5 and Tables 2 and 6 are very close. The slight differences are due to rounding.

Table 3: Min Uniform Extreme Interval Values when $\mathrm{a}=0$ and $\mathrm{b}=1$ (Jance)

\begin{tabular}{cccccccc}
\hline \hline $\mathbf{n}$ & $\mathbf{p}=\mathbf{0 . 0 1}$ & $\mathbf{p = 0 . 0 5}$ & $\mathbf{p}=\mathbf{0 . 1 0}$ & $\mathbf{p = 0 . 5 0}$ & $\mathbf{p = 0 . 9 0}$ & $\mathbf{p}=\mathbf{0 . 9 5}$ & $\mathbf{p}=\mathbf{0 . 9 9}$ \\
\hline 1 & 0.01000 & 0.05000 & 0.10000 & 0.50000 & 0.90000 & 0.95000 & 0.99000 \\
2 & 0.00501 & 0.02532 & 0.05132 & 0.29289 & 0.68377 & 0.77639 & 0.90000 \\
3 & 0.00334 & 0.01695 & 0.03451 & 0.20630 & 0.53584 & 0.63160 & 0.78456 \\
4 & 0.00251 & 0.01274 & 0.02600 & 0.15910 & 0.43766 & 0.52713 & 0.68377 \\
5 & 0.00201 & 0.01021 & 0.02085 & 0.12945 & 0.36904 & 0.45072 & 0.60189 \\
10 & 0.00100 & 0.00512 & 0.01048 & 0.06697 & 0.20567 & 0.25887 & 0.36904 \\
25 & 0.00040 & 0.00205 & 0.00421 & 0.02735 & 0.08799 & 0.11293 & 0.16824 \\
50 & 0.00020 & 0.00103 & 0.00211 & 0.01377 & 0.04501 & 0.05816 & 0.08799 \\
75 & 0.00013 & 0.00068 & 0.00140 & 0.00920 & 0.03023 & 0.03916 & 0.05956 \\
100 & 0.00010 & 0.00051 & 0.00105 & 0.00691 & 0.02276 & 0.02951 & 0.04501 \\
\hline
\end{tabular}

Table 4: Max Uniform Extreme Interval Values when $a=0$ and $b=1$ (Jance)

\begin{tabular}{cccccccc}
\hline \hline $\mathbf{n}$ & $\mathbf{p = 0 . 0 1}$ & $\mathbf{p = 0 . 0 5}$ & $\mathbf{p = 0 . 1 0}$ & $\mathbf{p = 0 . 5 0}$ & $\mathbf{p = 0 . 9 0}$ & $\mathbf{p = 0 . 9 5}$ & $\mathbf{p = 0 . 9 9}$ \\
\hline 1 & 0.01000 & 0.05000 & 0.10000 & 0.50000 & 0.90000 & 0.95000 & 0.99000 \\
2 & 0.10000 & 0.22361 & 0.31623 & 0.70711 & 0.94868 & 0.97468 & 0.99499 \\
3 & 0.21544 & 0.36840 & 0.46416 & 0.79370 & 0.96549 & 0.98305 & 0.99666 \\
4 & 0.31623 & 0.47287 & 0.56234 & 0.84090 & 0.97400 & 0.98726 & 0.99749 \\
5 & 0.39811 & 0.54928 & 0.63096 & 0.87055 & 0.97915 & 0.98979 & 0.99799 \\
10 & 0.63096 & 0.74113 & 0.79433 & 0.93303 & 0.98952 & 0.99488 & 0.99900 \\
25 & 0.83176 & 0.88707 & 0.91201 & 0.97265 & 0.99579 & 0.99795 & 0.99960 \\
50 & 0.91201 & 0.94184 & 0.95499 & 0.98623 & 0.99789 & 0.99897 & 0.99980 \\
75 & 0.94044 & 0.96084 & 0.96977 & 0.99080 & 0.99860 & 0.99932 & 0.99987 \\
100 & 0.95499 & 0.97049 & 0.97724 & 0.99309 & 0.99895 & 0.99949 & 0.99990 \\
\hline
\end{tabular}

Table 5: Min Log-Logistic Extreme Interval Values when $\alpha=1$ and $\beta=1$

\begin{tabular}{cccccccc}
\hline \hline $\mathbf{n}$ & $\mathbf{p = 0 . 0 1}$ & $\mathbf{p = 0 . 0 5}$ & $\mathbf{p = 0 . 1 0}$ & $\mathbf{p = 0 . 5 0}$ & $\mathbf{p = 0 . 9 0}$ & $\mathbf{p = 0 . 9 5}$ & $\mathbf{p = 0 . 9 9}$ \\
\hline 1 & 0.01010 & 0.05263 & 0.11111 & 1.00000 & 9.00000 & 19.00000 & 99.00000 \\
2 & 0.00504 & 0.02598 & 0.05410 & 0.41421 & 2.16226 & 3.47207 & 9.00000 \\
3 & 0.00335 & 0.01724 & 0.03574 & 0.25992 & 1.15443 & 1.71444 & 3.64166 \\
4 & 0.00252 & 0.01290 & 0.02669 & 0.18920 & 0.77828 & 1.11475 & 2.16226 \\
5 & 0.00201 & 0.01032 & 0.02129 & 0.14870 & 0.58489 & 0.82057 & 1.51187 \\
10 & 0.00100 & 0.00515 & 0.01059 & 0.07178 & 0.25892 & 0.34929 & 0.58489 \\
25 & 0.00040 & 0.00205 & 0.00423 & 0.02812 & 0.09648 & 0.12731 & 0.20227 \\
50 & 0.00020 & 0.00103 & 0.00211 & 0.01396 & 0.04713 & 0.06175 & 0.09648 \\
75 & 0.00013 & 0.00068 & 0.00140 & 0.00929 & 0.03117 & 0.04076 & 0.06333 \\
100 & 0.00010 & 0.00051 & 0.00105 & 0.00696 & 0.02329 & 0.03041 & 0.04713 \\
\hline
\end{tabular}


Table 6: Max Log-Logistic Extreme Interval Values when $\alpha=1$ and $\beta=1$

\begin{tabular}{cccccccc}
\hline \hline $\mathbf{n}$ & $\mathbf{p = 0 . 0 1}$ & $\mathbf{p = 0 . 0 5}$ & $\mathbf{p = 0 . 1 0}$ & $\mathbf{p = 0 . 5 0}$ & $\mathbf{p = 0 . 9 0}$ & $\mathbf{p = 0 . 9 5}$ & $\mathbf{p = 0 . 9 9}$ \\
\hline 1 & 0.01010 & 0.05263 & 0.11111 & 1.00000 & 9.00000 & 19.00000 & 99.00000 \\
2 & 0.11111 & 0.28801 & 0.46248 & 2.41425 & 18.48558 & 38.49447 & 198.60080 \\
3 & 0.27460 & 0.58328 & 0.86623 & 3.84731 & 27.97711 & 57.99705 & 298.40120 \\
4 & 0.46248 & 0.89707 & 1.28488 & 5.28536 & 37.46154 & 77.49294 & 397.40637 \\
5 & 0.66143 & 1.21867 & 1.70973 & 6.72499 & 46.96163 & 96.94319 & 496.51244 \\
10 & 1.70973 & 2.86294 & 3.86216 & 13.93206 & 94.41985 & 194.31250 & 999.00000 \\
25 & 4.94389 & 7.85504 & 10.36493 & 35.56307 & 236.52969 & 486.80488 & 2499.00000 \\
50 & 10.36493 & 16.19395 & 21.21729 & 71.62164 & 472.93365 & 969.87379 & 4999.00000 \\
75 & 15.78979 & 24.53626 & 32.07972 & 107.69565 & 713.28571 & 1469.58824 & 7691.30769 \\
100 & 21.21729 & 32.88682 & 42.93673 & 143.71780 & 951.38095 & 1959.78431 & 9999.00000 \\
\hline
\end{tabular}

\section{APPLICATION}

There are four machines whose time to failure follows a log-logistic distribution with parameters $\alpha=$ 1 and $\beta=1$. Suppose one wants to know the time, with $99 \%$ certainty, when the first unit and the last unit will fail. In Table 1 , the min extreme interval value for $\mathrm{n}=4$ and probability $\mathrm{p}=0.99$ is 2.16228 . In Table 2 the max extreme interval value is 397.49686 for $\mathrm{n}=4$ and probability $\mathrm{p}=0.99$. Therefore, there is a $99 \%$ chance that the first unit failure will occur by 2.16228 and a $99 \%$ chance that the last of the four units will fail by 397.49686 .

\section{CONCLUSIONS}

The paper discusses the min and max log-logistic extreme interval values. It is shown how the log-logistic extreme interval values can be found from the uniform extreme interval values. An application and tables displaying some of the extreme interval values for the log-logistic and uniform distributions are presented.

\section{AUTHOR INFORMATION}

Marsha L. Jance received her Ph.D. in Management Science from Illinois Institute of Technology Stuart School of Business in Chicago, Illinois. She is an Assistant Professor of Business Administration at Indiana University East in Richmond, Indiana. E-mail: mjance@iue.edu. Corresponding author.

Nick T. Thomopoulos is a professor at the Stuart School of Business at Illinois Institute of Technology. Nick has degrees in business, mathematics, and industrial engineering. He is the author of four books: Quantitative Methods Along the Supply Chain, Atlantic Books, 2011, Assembly Line Systems, Hayden Books, 1973, Applied Forecasting Methods, Prentice Hall, 1980, and Strategic Inventory Management and Planning, Hitchcock Publishing Co., 1990. E-mail: thomop@stuart.iit.edu.

\section{REFERENCES}

1. Hines, William W., Douglas C. Montgomery, David M. Goldsman, and Connie M. Borror. Probability and Statistics in Engineering Fourth Edition. John Wiley \& Sons, Inc., 2003.

2. Jance, Marsha L. Calculating Min and Max Extreme Interval Values for Various Distributions. Doctoral dissertation. Chicago, IL: Illinois Institute of Technology Stuart School of Business, 2007.

3. Jance, Marsha L. and Nick T. Thomopoulos. "Min and Max Triangular Extreme Interval Values and Statistics." Journal of Business and Economics Research 8.9 (2010): 139-146.

4. Law, Averill M., and W. David Kelton. Simulation Modeling and Analysis Third Edition. McGraw-Hill, 2000.

5. $\quad$ MATLAB: Version 7.8.0.347, The MathWorks, 2009.

6. Microsoft Excel: Professional Plus 2010, Redmond, WA: Microsoft Corporation, 2010. 
NOTES 